Volume 3, Issue 1, February 2018, Pages: 240, DOI: http://dx.doi.org/10.19082/ah240

\title{
TOPICAL BEE HONEY FOR SEVERELY INFECTED PERINEAL AND EPISIOTOMY WOUNDS
}

\author{
Ahmed TageldinAbdelhafiz ${ }^{1}$, Jihan Abdelmoneim ${ }^{1}$, Mohamed Khoder ${ }^{2}$
}

1: Asiut Clinic for Gynecology and Obstetrics

2: Unit of Honey Bee Science, Faculty of Agriculture, Assiut University

\section{TYPE OF ARTICLE: CONFERENCE ABSTRACT}

\begin{abstract}
Aim: to evaluate therapeutic efficacy of topical honey as wound dressing in cases of perennial infections following gynecologic surgeries and episiotomies.

Methods: Sixty-one patients with either post-perennial repair or post-episiotomy severe wound infections were recruited, and allocated into two groups. Group I (31) received crude Egyptian bee honey applications, and Group II (30) had local antiseptics. Both groups have systemic antibiotics. The honey amount was applied under these conditions: depended on amount of exudate; in general $10 \mathrm{cc}$ for a 5-cm dressing, twice daily as beginning; if sticky: more, if gapped: filled with honey before applying the dressing pad, peri-wound inflamed area: included in the dressing, occlusive secondary dressing applied to prevent ooze.

Results: Infection data included: 1) same general (fever and malaise) and local (pain, tenderness, hotness and discharge) symptoms in the 2 groups , 2) onset of infection: 3-days in group I and 2-99 days in group II., 3) bacterial isolates: stash., strept, Pseudomonas spp, E. coli, bacteroides and clostridia in the 2 groups, 4) antimicrobial used: the same for the 2 groups: Gentamycin, flucloxacillin, metronidazole, tobramycin and clindamycin. Cure responses of the 2 groups: Group I has shown: a) faster wound healing (11.8 days vs. $24.7 ; \mathrm{P}<.001 ; \mathrm{b}$ ) shorter hospital stay ( 6.5 vs. 12,2 days, $\mathrm{P}<.01)$; c) less need for secondary intervention ( 3 secondary stitches vs. $8, \mathrm{P}<.001)$; d) faster bacteriologic cure (6.5 DAYS VS. 17.7; $\mathrm{P}<.001$ ).

Conclusion: Honey is a very effective and inexpensive treatment for severe perennial wound sepsis.

KEYWORDS: Ancient, Egypt, Care
\end{abstract}

\footnotetext{
Abstracts of Second International Conference on Health Sciences and Medical Technologies, 10-12 October 2017, Tlemcen, Algeria (ICHSMT-17)

(C) 2018 The Authors. This is an open access article under the terms of the Creative Commons Attribution-NonCommercialNoDerivs License, which permits use and distribution in any medium, provided the original work is properly cited, the use is non-commercial and no modifications or adaptations are made.
} 